\title{
Voluntary/Involuntary Admissions/Readmissions of Psychiatric Patients in a University Hospital in Turkey From 2008 to 2016
}

\author{
Bahadır Geniş ${ }^{1 *}$, Behçet Coşar ${ }^{1}$, Selçuk Candansayar ${ }^{1}$, Nermin Gürhan $^{2}$ \\ ${ }^{1}$ Department of Psychiatry, Faculty of Medicine, Gazi University, Ankara, Turkey \\ ${ }^{2}$ Department of Nursing, Faculty of Health Sciences, Gazi University, Ankara, Turkey \\ *Corresponding Author: Bahadır Geniş, M.D., Psychiatrist, Department of Psychiatry, Faculty of Medicine, Gazi \\ University, Ankara, Turkey. Tel: +90-312-2026699, Email: bahadirgenis06@gmail.com
}

Received November 30, 2017; Accepted May 22, 2018; Online Published September 22, 2018

\begin{abstract}
Background: The treatment and hospitalization of psychiatric patients has been a dilemma for many years. Many countries have different specific legislations regarding the hospitalization and treatment of mental patients.

Objective: In the current study, 4100 voluntary/involuntary psychiatric admissions and readmissions to a university hospital in Turkey were investigated, and patient groups were compared in terms of demographic variables and psychiatric diagnoses based on DSM IV-TR.

Methods: The records of patients who had been hospitalized approximately 4-6 weeks were reviewed by two psychiatrists, and the patients were then divided into groups on the basis of single/multiple admissions and voluntary/involuntary admissions. The groups were compared based on psychiatric diagnoses.

Results: Schizophrenia was the most common diagnosis in $71.5 \%(n=865)$ of patients with multiple admissions. The second most common diagnosis was bipolar affective disorder with $13.1 \%(\mathrm{n}=159)$. The rate of schizophrenia in both voluntary and involuntary hospitalizations was significant $(34.5 \%$ and $54.6 \%$, respectively). However, depression, the second most common diagnosis requiring hospitalization with a rate of $23.2 \%$ of voluntary hospitalizations, accounted for only $3.7 \%$ of involuntary hospitalizations.

Conclusion: Males constituted almost $75 \%$ of the single admission group. This difference may result from the socioeconomic and cultural profile of Turkey, as mental disorders make marriage impossible and are hidden in females suffering from them. Different findings from different cultures on single/multiple admissions and voluntary/involuntary admissions of patients lead to the conclusion that specific legislation covering treatment or hospitalization for mental disorders is needed in every country.

Keywords: Hospitalization, Voluntary, Involuntary, Readmission, Admission
\end{abstract}

\section{Background}

It has long been known that there is a dynamic relationship between concepts of mental illness, the treatment of the mentally ill, and the law. The World Health Organization (WHO) expert committees in mental health over the past 40 years have called attention to the need to consider legal matters in various fields of mental health including the hospitalization of mental patients and the development of community-based mental health services. ${ }^{1}$

In a comparative legislative survey done by the WHO in the 1970s, 43 countries were evaluated. The selection included countries of varying population sizes, levels of socioeconomic development, political systems, structures and histories, cultural backgrounds, patterns of health services, and mental health care systems. ${ }^{1}$ Twelve countries were found to have no specific legislation covering treatment or hospitalization for mental disorders. These countries were classified as operating under informal systems. The remaining 31 countries were found to have specific mental health legislation and were classified as operating under formal systems. Unfortunately, there was no effective data for Turkey in this survey.

The Psychiatric Association of Turkey began work on a draft legislation in 1998, and the first proposal was released in 2006. ${ }^{2}$ The proposed bill supported both the patients rights to treatment and the clinical governance in mental health settings.

The current practice in Turkey is that the family of a

Copyright (C) 2018 The Author(s). This is an open-access article distributed under the terms of the Creative Commons Attribution License (http:// creativecommons.org/licenses/by/4.0), which permits unrestricted use, distribution, and reproduction in any medium, provided the original work is properly cited. 
patient can either refuse admission or discharge the patient by withdrawing consent for medical service. Specific legislation for involuntary admissions is still lacking. ${ }^{3}$

Some studies have examined possible differences between voluntary/involuntary and single/multiple psychiatric admissions. The results of these studies are conflicting. While some researchers have indicated that there is no difference in the demographic profiles of voluntary and involuntary patients, ${ }^{3,4}$ others have pointed out that voluntary patients are more likely to be female $e^{5,6}$ and married. ${ }^{6}$ It was indicated that involuntary patients are more likely to live alone, ${ }^{3}$ to be male, ${ }^{5}$ and to be elderly. ${ }^{7}$ Conversely, in one study, the only factor that was significantly associated with involuntary readmissions was found to be ethnic group. ${ }^{8}$ The profile of the typical patient most frequently hospitalized was described as a young, unmarried male with schizophrenia. ${ }^{9}$

Schizophrenia and psychosis not elsewhere classified were said to be in the subgroup with a high risk of readmission, ${ }^{10,11}$ whereas in other investigations voluntary and involuntary patients have been described as presenting similar diagnostic profiles. ${ }^{4,7,9}$

These conflicting results may be explained by methodological and procedural differences in the studies due to the varied criteria across different countries. A systematic literature review on involuntary vs. voluntary hospital admission ${ }^{12}$ stated the importance of significant variations in the methodological quality of studies coming mostly from North American and European countries. In particular, sample size estimation, lack of clear follow-up time points, and the absence of standardized instruments used to assess clinical outcomes were stated to be the main limitations of these studies. Length of stay, readmission risk, and risk of involuntary readmission were at least equal to and often greater than that of involuntary patients. Psychiatric illness expressed through aggressive behavior generally requires involuntary hospitalization. In Turkey, there is no standardized criteria or rule permitting involuntary admissions. Those persons presenting a danger to themselves or others, lacking the competence to care for themselves, or suffering from a mental disorder or psychiatric illness expressed through aggressive behavior and having been brought by police are hospitalized involuntarily upon the evaluation of a single psychiatrist.

\section{Objective}

In the current study, 4100 voluntary/involuntary psychiatric admissions and readmissions in a university hospital in Ankara, Turkey were investigated. The demographic variables and psychiatric diagnosis according to DSM IVTR of established patient groups were compared..$^{13}$

\section{Methods}

The present study was conducted at Gazi University School of Medicine, Psychiatry Department, Ankara, Turkey. The inpatient service consists of 30 beds serving adult psychiatric patients, and an average of 550-600 people stay in inpatient service each year.

The records of patients admitted to the hospital between 2008 and 2016 were reviewed by two psychiatrists. Patients under 18 years of age and less than 10 days on the day of hospitalization were excluded from the study. Patients whose socio-demographic information was lacking or whose primary diagnosis was unclear (a rare situation) were also excluded from the study. Furthermore, patients diagnosed with an anxiety disorder that could not be assessed due to a problem with the registration system were excluded from the study. All other patients were included in the study.

The records of patients admitted after 2012 were scanned from the computer registry system, while those of patients admitted between 2008 and 2012 were scanned from archived files. Primary diagnoses, age, and gender variables of the patients were obtained when the screening was performed in the computer environment. The data on single/multiple hospitalizations, voluntary/involuntary hospitalizations, educational status, and marital status of these patients was also investigated individually for each patient in the computer environment. For patients prior to 2012 , data on all the variables were obtained by scanning archived files.

The patients were divided into groups on the basis of single admission (SA)/multiple admissions (MA), and voluntary admission (VA)/involuntary admission (IA). Those patients representing a danger to themselves or others, lacking the competence to care for themselves, apparently suffering from a mental disorder, and brought to the hospital by police were categorized in the IA group. Additionally, through a judicial decision, those patients who required treatment in the inpatient service and those who had no insight into their illness were included in the IA group of patients.

The pre-2012 archived records, the computer registration system between 2012 and 2016, and the records of each patient between these years were evaluated as SA, i.e. patients admitted to the inpatient service only once. Based on these records, patients who were treated more than once in the inpatient service were considered MA.

The diagnosis and demographic information of at the time of the most recent admission of patients with MA was used in this study. Similarly, voluntary or IA was assessed according to the most recent admission. Thus, each patient was included only once in the data.

Voluntary/involuntary and single/multiple admission groups were compared on demographic variables such as gender, age, marital status, and educational level. They were also compared on the basis of psychiatric diagnosis according to DSM IV-TR: (1) Schizophrenia, (2) Psychotic disorders not elsewhere classified, (3) Depression, (4) Delusional disorder, (5) Bipolar affective disorder, (6) Personality disorder, (7) Organic mental disorder, (8) Others.

In the statistical analysis, chi square tests were used to assess the differences in psychiatric diagnoses and 
demographic characteristics of voluntary/involuntary and single/multiple admission patients. Statistical significance was accepted as $P<0.05$. Data was evaluated using SPSS 22.

\section{Results}

From a total of 4100 admissions, $70.5 \%(n=2890)$ were SA, while $29.5 \%(n=1210)$ were MA.

The distribution of diagnoses between SA and MA groups was statistically significant $\left(\chi^{2}=469.01\right.$, sd: $\left.7, P<0.001\right)$ (Table 1). Though the first 3 diagnostic groups were the same in both admissions groups, their percentages were different. While the top three diagnoses in the SA group were schizophrenia $(35.6 \%, \mathrm{n}=1030)$, bipolar disorder $(22.4 \%, \mathrm{n}=648)$, and psychotic disorder not elsewhere classified $(19.9 \%, n=574)$, the percentages of these three diagnostic groups in the MA group were $71.5 \%(n=865)$, $13.1 \%(n=159)$, and $7.4 \%(n=89)$, respectively.

The demographic characteristics of the MA and SA patients were found to be different (Table 2).

In general, $68.6 \%(\mathrm{n}=2813)$ and $31.4 \%(\mathrm{n}=1287)$ of patients were male and female, respectively. Among the SA patients, $74.7 \%(n=2159)$ were male, whereas $54.0 \%(\mathrm{n}=654)$ of the 1210 MA patients were male. The percentages of female patients in the SA and MA groups were $25.3 \%(\mathrm{n}=731)$ and $46.0 \%(\mathrm{n}=556)$, respectively $\left(\chi^{2}=168.97\right.$, sd: $\left.1, P<0.001\right)$.

Furthermore, $24.9 \%(\mathrm{n}=721)$ of SA patients were in the $45-54$ years of age range, whereas $26.9 \%(n=325)$ of MA patients were in the 35-44 years of age range $\left(\chi^{2}=76.19\right.$, sd: $5, P<0.001)$.

In the SA and MA groups, 33.3\% ( $\mathrm{n}=961)$ and $50.8 \%$ ( $=615$ ) of the couples, respectively, were married. However, the divorce rate was as high as $28.7 \%(n=828)$ in the SA group and only $16.5 \%(\mathrm{n}=200)$ in the MA group $\left(\chi^{2}=\right.$ 134.27, sd: $3, P<0.001)$. Most patients in both groups had a secondary level education, but more patients in the SA group $(23.3 \%, \mathrm{n}=673)$ than in the MA group $(8.5 \%, \mathrm{n}=$ $103)$ had a post-secondary education level $\left(\chi^{2}=228.64\right.$, sd: $3, P<0.001)$.

From a total of 4100 admissions, $41.7 \%(n=1709)$ were

Table 1. Primary Diagnosis of Single and Multiple Admissions

\begin{tabular}{|c|c|c|c|c|c|c|}
\hline \multirow{2}{*}{ Diagnosis } & \multicolumn{2}{|c|}{ Single Admission $(n=2890)$} & \multicolumn{2}{|c|}{ Multiple Admissions $(n=1210)$} & \multicolumn{2}{|c|}{ Total $(n=4100)$} \\
\hline & No. & $\%$ & No. & $\%$ & No. & $\%$ \\
\hline Schizophrenia & 1030 & 35.6 & 865 & 71.5 & 1895 & 46.2 \\
\hline Psychotic disorder not classified elsewhere & 574 & 19.9 & 89 & 7.4 & 663 & 16.2 \\
\hline Depression & 434 & 15.0 & 51 & 4.2 & 485 & 11.8 \\
\hline Delusional disorder & 51 & 1.8 & 12 & 1.0 & 63 & 1.5 \\
\hline Bipolar affective disorder & 648 & 22.4 & 159 & 13.1 & 807 & 19.7 \\
\hline Personality disorder & 82 & 2.8 & 15 & 1.2 & 97 & 2.4 \\
\hline Organic mental disorder & 47 & 1.6 & 3 & 0.2 & 50 & 1.2 \\
\hline Others & 24 & 0.8 & 16 & 1.3 & 40 & 1.0 \\
\hline Total & 2890 & 100 & 1210 & 100 & 4100 & 100 \\
\hline
\end{tabular}

$\chi^{2}=469.01, \mathrm{Sd}=7, P<0.001$

Table 2. Demographic Characteristics of Patients With Single and Multiple Admissions

\begin{tabular}{|c|c|c|c|c|c|c|c|c|c|c|}
\hline \multirow{2}{*}{\multicolumn{2}{|c|}{ Demographic Variable }} & \multicolumn{2}{|c|}{ Single Admission $(n=2890)$} & \multicolumn{2}{|c|}{ Multiple Admissions $(n=1210$ ) } & \multicolumn{2}{|c|}{ Total $(n=4100)$} & \multicolumn{3}{|c|}{ Analysis } \\
\hline & & No. & $\%$ & No. & $\%$ & No. & $\%$ & $\chi^{2}$ & Sd & $\boldsymbol{P}$ \\
\hline \multirow{2}{*}{ Sex } & Male & 2159 & 74.7 & 654 & 54.0 & 2813 & 68.6 & \multirow{2}{*}{168.97} & \multirow{2}{*}{1} & \multirow{2}{*}{$<0.001$} \\
\hline & Female & 731 & 25.3 & 556 & 46.0 & 1287 & 31.4 & & & \\
\hline \multirow{6}{*}{ Age (y) } & $18-24$ & 306 & 10.6 & 225 & 18.6 & 531 & 13.0 & \multirow{6}{*}{76.19} & \multirow{6}{*}{5} & \multirow{6}{*}{$<0.001$} \\
\hline & $25-34$ & 676 & 23.4 & 286 & 23.6 & 962 & 23.5 & & & \\
\hline & $35-44$ & 696 & 24.1 & 325 & 26.9 & 1021 & 24.9 & & & \\
\hline & $45-54$ & 721 & 24.9 & 200 & 16.5 & 921 & 22.5 & & & \\
\hline & $55-64$ & 331 & 11.5 & 124 & 10.2 & 455 & 11.1 & & & \\
\hline & $\geq 65$ & 160 & 5.5 & 50 & 4.1 & 210 & 5.1 & & & \\
\hline \multirow{4}{*}{ Marital status } & Single & 794 & 27.5 & 316 & 26.1 & 1110 & 27.1 & \multirow{4}{*}{134.27} & \multirow{4}{*}{3} & \multirow{4}{*}{$<0.001$} \\
\hline & Married & 961 & 33.3 & 615 & 50.8 & 1576 & 38.4 & & & \\
\hline & Divorced & 828 & 28.7 & 200 & 16.5 & 1028 & 25.1 & & & \\
\hline & Widowed & 307 & 10.6 & 79 & 6.5 & 386 & 9.4 & & & \\
\hline \multirow{4}{*}{ Education } & Below Elementary & 94 & 3.3 & 111 & 9.2 & 205 & 5.0 & \multirow{4}{*}{228.64} & \multirow{4}{*}{3} & \multirow{4}{*}{$<0.001$} \\
\hline & Elementary & 831 & 28.8 & 250 & 20.7 & 1081 & 26.4 & & & \\
\hline & Secondary & 1292 & 44.7 & 746 & 61.7 & 2038 & 49.7 & & & \\
\hline & Postsecondary & 673 & 23.3 & 103 & 8.5 & 776 & 18.9 & & & \\
\hline
\end{tabular}


VA, while 58.3\% $(n=2391)$ were IA. The distribution of diagnoses between the VA and IA groups showed a statistically significant difference $\left(\chi^{2}=477.03\right.$, sd: 7 , $P<0.001)$ (Table 3$)$. While the top three diagnoses in the VA group were schizophrenia $(34.5 \%, \mathrm{n}=589)$, depression $(23.2 \%, \mathrm{n}=396)$, and bipolar affective disorder $(22.1 \%, \mathrm{n}$ $=377)$, in the IA group, schizophrenia $(54.6 \%, \mathrm{n}=1306)$, bipolar affective disorder $(18.0 \%, \mathrm{n}=430)$, and psychotic disorder not classified elsewhere $(17.4 \%, \mathrm{n}=417)$ were the top three most frequent diagnoses.

The demographic characteristics of the VA and IA patients were also different (Table 4 ). Of the VA patients, $59.4 \%(n=1016)$ were male, whereas $75.2 \%(n=1797)$ of patients in the IA group were male. The percentages of female patients in the VA and IA groups were $40.6 \%$ ( $\mathrm{n}=$ $693)$ and $24.8 \%(\mathrm{n}=594)$, respectively $\left(\chi^{2}=114.16\right.$, sd: 1 , $P<0.001)$.

In the VA group, $26.0 \%(\mathrm{n}=445)$ of patients were in the 35-44 years of age range, whereas in the IA group, the most frequently seen age ranges were $25-34$ and $45-54$. $\left(\chi^{2}\right.$ $=113.40$, sd: $5, P<0.001)$.
In both the VA and IA groups, most of the patients were married. The percentage of married patients for VA and IA groups was $38.6 \%$ and $38.3 \%$, respectively. However, the divorce rate in the IA group was as high as $28.1 \%$, whereas this rate was $20.8 \%$ in the VA group $\left(\chi^{2}=196.47\right.$, sd: 3 , $P<0.001)$.

Most patients in each group had a secondary level education, but more patients in the VA group (52.9\%) had a post-secondary level of education than the IA group (47.4\%) $\left(\chi^{2}=69.37\right.$, sd: $\left.3, P<0.001\right)$.

\section{Discussion}

Schizophrenia has a long-term deteriorating course and manifests itself with exacerbations; thus, it is the most common diagnosis in the MA group, as was expected. Relapse is also common with bipolar affective disorder (BAD), and BAD was the second most common diagnosis in the MA group as it was in the SA group. Many studies have investigated and identified which factors are effective in readmission to the hospital, and a diagnosis of schizophrenia, schizoaffective disorder, or BAD, ${ }^{14,15}$ male

Table 3. Primary Diagnoses of Voluntarily and Involuntarily Admitted Psychiatric Patients

\begin{tabular}{|c|c|c|c|c|c|c|}
\hline \multirow{2}{*}{ Diagnosis } & \multicolumn{2}{|c|}{ Voluntary $(n=1709)$} & \multicolumn{2}{|c|}{ Involuntary $(\mathrm{n}=2391)$} & \multicolumn{2}{|c|}{ Total $(n=4100)$} \\
\hline & No. & $\%$ & No. & $\%$ & No. & $\%$ \\
\hline Schizophrenia & 589 & 34.5 & 1306 & 54.6 & 1895 & 46.2 \\
\hline Psychotic disorder not classified elsewhere & 246 & 14.4 & 417 & 17.4 & 663 & 16.2 \\
\hline Depression & 396 & 23.2 & 89 & 3.7 & 485 & 11.8 \\
\hline Delusional disorder & 11 & 0.6 & 52 & 2.2 & 63 & 1.5 \\
\hline Bipolar affective disorder & 377 & 22.1 & 430 & 18.0 & 807 & 19.7 \\
\hline Personality disorder & 48 & 2.8 & 49 & 2.0 & 97 & 2.4 \\
\hline Organic mental disorder & 9 & 0.5 & 41 & 1.7 & 50 & 1.2 \\
\hline Others & 33 & 1.9 & 7 & 0.3 & 40 & 1.0 \\
\hline Total & 1709 & 100 & 2391 & 100 & 4100 & 100 \\
\hline
\end{tabular}

$\chi^{2}=477.03, \mathrm{Sd}=7, P<0.001$.

Table 4. Demographic Characteristics of Voluntary and Involuntary Admitted Psychiatric Patients

\begin{tabular}{|c|c|c|c|c|c|c|c|c|c|c|}
\hline \multirow{2}{*}{\multicolumn{2}{|c|}{ Demographic Variable }} & \multicolumn{2}{|c|}{ Voluntary $(n=1709)$} & \multicolumn{2}{|c|}{ Involuntary ( $\mathrm{n}=2391$ ) } & \multicolumn{2}{|c|}{ Total $(n=4100)$} & \multicolumn{3}{|c|}{ Analysis } \\
\hline & & No. & $\%$ & No. & $\%$ & No. & $\%$ & $\chi^{2}$ & Sd & $P$ \\
\hline \multirow{2}{*}{ Sex } & Male & 1016 & 59.4 & 1797 & 75.2 & 2813 & 68.6 & \multirow{2}{*}{114.16} & \multirow{2}{*}{1} & \multirow{2}{*}{$<0.001$} \\
\hline & Female & 693 & 40.6 & 594 & 24.8 & 1287 & 31.4 & & & \\
\hline \multirow{6}{*}{ Age $(y)$} & $18-24$ & 307 & 18 & 224 & 9.4 & 531 & 13.0 & \multirow{6}{*}{113.4} & \multirow{6}{*}{5} & \multirow{6}{*}{$<0.001$} \\
\hline & $25-34$ & 337 & 19.7 & 625 & 26.1 & 962 & 23.5 & & & \\
\hline & $35-44$ & 445 & 26 & 576 & 24.1 & 1021 & 24.9 & & & \\
\hline & $45-54$ & 305 & 17.8 & 616 & 25.8 & 921 & 22.5 & & & \\
\hline & $55-64$ & 210 & 12.3 & 245 & 10.2 & 455 & 11.1 & & & \\
\hline & $\geq 65$ & 105 & 6.1 & 105 & 4.4 & 210 & 5.1 & & & \\
\hline \multirow{4}{*}{ Marital status } & Single & 409 & 23.9 & 701 & 29.3 & 1110 & 27.1 & \multirow{4}{*}{196.47} & \multirow{4}{*}{3} & \multirow{4}{*}{$<0.001$} \\
\hline & Married & 660 & 38.6 & 916 & 38.3 & 1576 & 38.4 & & & \\
\hline & Divorced & 355 & 20.8 & 673 & 28.1 & 1028 & 25.1 & & & \\
\hline & Widowed & 285 & 16.7 & 101 & 4.2 & 386 & 9.4 & & & \\
\hline \multirow{4}{*}{ Education } & Below Elementary & 70 & 4.1 & 135 & 5.6 & 205 & 5.0 & \multirow{4}{*}{69.37} & \multirow{4}{*}{3} & \multirow{4}{*}{$<0.001$} \\
\hline & Elementary & 350 & 20.5 & 731 & 30.6 & 1081 & 26.4 & & & \\
\hline & Secondary & 904 & 52.9 & 1134 & 47.4 & 2038 & 49.7 & & & \\
\hline & Postsecondary & 385 & 22.5 & 391 & 16.4 & 776 & 18.9 & & & \\
\hline
\end{tabular}


gender, ${ }^{16}$ young age,,${ }^{9,14}$ being unmarried, ${ }^{17}$ and involuntary hospitalization. ${ }^{18,19}$

Males comprised the predominate gender in both SA and MA groups. The percentage of males constituted almost $3 / 4^{\text {th }}$ of the SA group. In a study from India, female gender was found to be predictive of readmission. ${ }^{20}$ In contrast, the United States, ${ }^{16}$ Canada, ${ }^{14}$ and Israel ${ }^{21}$ have shown that the male gender is a risk factor for recurrent admission. These differences may result from the socioeconomical and cultural profiles of the countries. In Turkey, males are expected to work and earn a living, and any intervention, like disease, receives medical help; females are expected to stay at home, so functional impairment may be hidden. Mostly in rural areas, the stigma for insanity, which makes marriage impossible, leads these mental disorders to be hidden in females suffering from them. Any relapsing disorder, like schizophrenia or BAD, necessitates medical help, and regardless of gender, people seek medical help. This tendency was seen in the MA group; i.e., the percentages of males and females were almost equal.

In the current study, $71 \%$ of MAs were diagnosed as schizophrenia. In many studies, schizophrenia was recognized as a risk factor for readmission. ${ }^{14,15}$ These results are consistent with those of the current study. In addition to schizophrenia, $\mathrm{BAD}^{15}$ and personality disorder ${ }^{22}$ were also identified as risk factors. The age range of 35-44 years seems to be the most frequent group in which MA take place, and the frequency of admissions declines in older ages. This results seems to stem from the nature of schizophrenia, where negative symptoms predominate and positive symptoms fade in the late course of the disease. In the SA group, there was not much difference among age groups; this result may arise from the homogeneity of the diagnostic groups; i.e. the percentages of schizophrenia, $\mathrm{BAD}$, depression, and psychotic disorder not elsewhere classified are closer to each other, whereas in the MA group, schizophrenia alone made up $3 / 4^{\text {th }}$ of all diagnoses.

Psychiatric disorders with psychotic features in which reality testing is disturbed (schizophrenia, psychotic disorder not classified elsewhere, and BAD) are more common in IAs, as was expected. IAs present at younger ages when schizophrenia usually first becomes evident. In agreement with the literature, male patients dominated the involuntary patient group..$^{5,623,24}$ No difference in marital status of patients was observed with regard to voluntary and IAs, but divorced patients made up the greater portion of the involuntary patient group. ${ }^{3,4}$ In a study from Turkey, it was found that patients who were not married are prominent in the involuntary group. ${ }^{23}$ In the current study, married people in both the VA and IA groups comprised the highest ratio. While the percentage of divorced couples in the VA group was $20.8 \%$, it was found to be $28.1 \%$ in the IA group (Table 4). The cultural structure of Turkey favors early marriage, that is, before the disease manifests itself, and the disease is usually accepted as faith so that families usually sustain their marriages. Fewer patients in the IA group had a post-secondary education, which may be the result of a disease intervening at early years of life, but low education level itself may also play a role in the lack of insight and failure to seek medical help, which may result in IAs.

In the current study, $58.3 \%$ of all psychiatric inpatient admissions were IAs. This rate is quite high compared to that of countries in the European Union. A study evaluating admissions between 1990-2000 reported that IAs comprised 5.8\% in Belgium, 12.5\% in France, $4.6 \%$ in Denmark, $17.7 \%$ in Germany and $21.6 \%$ in Finland ${ }^{25}$ of all psychiatric inpatient admissions. In Turkey, the total number of psychiatric inpatient services is inadequate compared to the number of psychiatric patients. Therefore, the admission of people with severe mental illnesses (psychotic disorder, bipolar affective disorder etc) has a greater priority for hospitalization than other mental illnesses. Those with severe mental illnesses have been reported to have higher rates of Ias. ${ }^{8,26}$ Hence, the high rate of IAs in Turkey seems to be due to the more frequent hospitalizations of those with severe mental illness.

In the current study, the subdiagnostic groups of BAD and personality disorders have not been investigated. Manic patients and depressive patients may differ in their admissions to the hospital. However, in a study evaluating $1374 \mathrm{BAB}$ patients, $76.2 \%$ of those with voluntary admission and $84 \%$ of those with IA were in the mania period. ${ }^{27}$ Although this study found that the rate of involuntary hospitalizations of manic patients was somewhat higher than that of voluntary hospitalizations, the rates may be close. It is a known fact that patients in the manic period are more agitated and aggressive. This can increase the involuntary hospitalization rate.

The patients in this study were included based only on the primary diagnosis. Comorbid psychiatric and physical illnesses were not evaluated. Alcohol and drug addictions are more common in patients with involuntary hospitalizations. This disease group is sometimes seen as a primary disease and sometimes other psychiatric diseases as comorbid. The fact that this diagnostic group is not evaluated indicates the limitations of the study.

In addition, it has been reported that treatment compliance, type of medication used in treatment, family support, socioeconomic status, and presence of positive symptoms in psychotic disorders may change both the number and the type of hospitalizations. The lack of data on these variables in the current study can be seen as a limitation.

In future studies, variables such as drug adherence, a single diagnostic group, family support, medication used (antipsychotic/antidepressant/anticonvulsant and subgroups, etc), comorbid alcohol/substance use, content of symptoms (positive/negative symptoms, etc) may be studied.

\section{Conclusion}

When all findings are evaluated together, it is obvious that involuntary hospitalizations are more frequent than 


\section{Research Highlights}

\section{What Is Already Known?}

Treatment and hospitalization of psychiatric patients has been considered to be a dilemma for many years. Many countries have different specific legislations for hospitalization and treatment of mental patients. Over the past 40 years the WHO Expert Committees in mental health have called attention to the need to consider legal matters in various fields of mental health including the hospitalization of mental patients and the development of community-based mental health services.

\section{What This Study Adds?}

A significant proportion of the multiple admissions in Turkey were found to be caused by schizophrenia patients. There is currently no full legal arrangement for hospitalization and treatment of these patients. In the present clinical practice, the approval of the family is crucial for the patient's admission to the hospital. There are still serious shortcomings in the legal regulations on involuntary hospitalizations. In this study, emphasis was placed on the lack of legal regulations on mental illnesses that were a significant number of hospitalizations.

voluntary hospitalizations. In addition, a vicious circle is formed when it is thought that this patient group is in MA. The absence of a legal regulation for this situation, which constitutes a significant part of psychiatric inpatients, creates both medical and legal problems.

There is no strict consensus on the involuntary hospitalization of mental patients in Turkey; thus, these results cannot be generalized for all of the country, but they can give some idea of the characteristics of the involuntarily/voluntarily admitted patients. Moreover, the results point out the necessity of specific legislation covering treatment or hospitalization for mental disorders.

\section{Authors' Contributions}

Study design: BG, BC, SC; Data collection and/or processing: BG, BC; Manuscript writing: BG, BC, SC, NG; Statistical analysis: BG; Literature review and critical revision: $\mathrm{BC}, \mathrm{SC}, \mathrm{NG}$.

\section{Conflict of Interest Disclosures \\ None.}

\section{Ethical Approval}

The ethical approval of the study was obtained from the Gazi University Ethics Commission.

\section{References}

1. Curran WJ, Harding TW. The law and mental health: harmonizing objectives, a comparative survey of existing legislation together with guidelines for its assessment and alternative approaches to its improvement. Geneva: World Health Organization; 1978:161.

2. Turkish Psychiatric Association Mental Health Law Draft.
Turkish Psychiatric Association Websites. http://www. psikiyatri.org.tr/299/ruh-sagligi-yasasi-taslaginin-yedi-yillikve-ruh-sagligi-platformunun-dort-aylik. Updated 06.01.2007. Accessed 01.12.2017

3. Cooper AJ. A clinical study of violence in patients referred on a Form I to a general hospital psychiatric unit. Can J Psychiatry. 1988;33(8):711-715. doi:10.1177/070674378803300808.

4. Okin RL. The relationship between legal status and patient characteristics in state hospitals. Am J Psychiatry. 1986;143(10):1233-1237. doi:10.1176/ajp.143.10.1233.

5. Riley R, Richman A. Involuntary hospitalization in Canadian psychiatric inpatient facilities, 1970-1978. Can J Psychiatry. 1983;28(7):536-541. doi:10.1177/070674378302800706.

6. Gove WR, Fain T. A comparison of voluntary and committed psychiatric patients. Arch Gen Psychiatry. 1977;34(6):669-676. doi:10.1001/archpsyc.1977.01770180055004.

7. Tremblay PF, King PR, Baines GR. Clinical and demographic characteristics of voluntary and involuntary psychiatric inpatients. Can J Psychiatry. 1994;39(5):297-299. doi:10.1177/ 070674379403900511.

8. Priebe S, Katsakou C, Amos T, et al. Patients' views and readmissions 1 year after involuntary hospitalisation. $\mathrm{Br} \quad J \quad P s y c h i a t r y . \quad 2009 ; 194(1): 49-54 . \quad$ doi:10.1192/bjp. bp. 108.052266 .

9. Sanguineti VR, Samuel SE, Schwartz SL, Robeson MR. Retrospective study of 2,200 involuntary psychiatric admissions and readmissions. Am J Psychiatry. 1996;153(3):392-396. doi:10.1176/ajp.153.3.392.

10. Addington D, Holley HL. A comparison of voluntary with remanded schizophrenics. Can J Psychiatry. 1989;34(2):89-93. doi:10.1177/070674378903400203.

11. Sanguineti VR, Brooks MO. Factors related to emergency commitment of chronic mentally ill patients who are substance abusers. Hosp Community Psychiatry. 1992;43(3):237-241. doi:10.1176/ps.43.3.237.

12. Kallert TW, Glockner M, Schutzwohl M. Involuntary vs voluntary hospital admission. A systematic literature review on outcome diversity. Eur Arch Psychiatry Clin Neurosci. 2008;258(4):195-209. doi:10.1007/s00406-007-0777-4.

13. American Psychiatric Association. Diagnostic and Statistical Manual of Mental Disorders. 4th ed. Washington DC: American Psychiatric Association; 2000.

14. Bernardo AC, Forchuk C. Factors associated with readmission to a psychiatric facility. Psychiatr Serv. 2001;52(8):1100-1102. doi:10.1176/appi.ps.52.8.1100.

15. Cuffel BJ, Held M, Goldman W. Predictive models and the effectiveness of strategies for improving outpatient follow-up under managed care. Psychiatr Serv. 2002;53(11):1438-1443. doi:10.1176/appi.ps.53.11.1438.

16. Houston KG, Mariotto M. Outcomes for psychiatric patients following first admission: relationships with voluntary and involuntary treatment and ethnicity. Psychol Rep. 2001;88(3 Pt 2):1012-1014. doi:10.2466/pr0.2001.88.3c.1012.

17. Riecher A, Rossler W, Loffler W, Fatkenheuer B. Factors influencing compulsory admission of psychiatric patients. Psychol Med. 1991;21(1):197-208. doi:10.1017/ S0033291700014781.

18. Feigon S, Hays JR. Prediction of readmission of psychiatric inpatients. Psychol Rep. 2003;93(3 Pt 1):816-818. doi:10.2466/ pr0.2003.93.3.816

19. Munk-Jorgensen P, Mortensen PB, Machon RA. Hospitalization patterns in schizophrenia. A 13-year follow-up. Schizophr Res. 1991;4(1):1-9. doi:10.1016/0920-9964(91)90004-B.

20. Singh H, Bhalchandra DA, Sarmukaddam S, Chaturvedi SK. Readmission of psychiatric patients in India: sociodemographic factors. Int J Cult Ment Health. 2014;7(4):398-409. doi:10.108 0/17542863.2013.835330. 
21. Fennig S, Rabinowitz J, Fennig S. Involuntary first admission of patients with schizophrenia as a predictor of future admissions. Psychiatr Serv. 1999;50(8):1049-1052. doi:10.1176/ ps.50.8.1049.

22. Chang CM, Lee $Y$, Lee $Y$, Yang MJ, Wen JK. Predictors of readmission to a medical-psychiatric unit among patients with minor mental disorders. Chang Gung Med J. 2001;24(1):34-43.

23. Gultekin BK, Celik S, Tihan A, Beskardes AF, Sezer U. Sociodemographic and Clinical Characteristics of Psychiatric Inpatients Hospitalized Involuntarily and Voluntarily in a Mental Health Hospital. Noro Psikiyatr Ars. 2013;50(3):216221. doi:10.4274/npa.y6245.

24. Zhou JS, Xiang YT, Zhu XM, et al. Voluntary and
Involuntary Psychiatric Admissions in China. Psychiatr Serv. 2015;66(12):1341-1346. doi:10.1176/appi.ps.201400566.

25. Salize HJ, Dressing H. Epidemiology of involuntary placement of mentally ill people across the European Union. $\mathrm{Br} J$ Psychiatry. 2004;184:163-168. doi:10.1192/bjp.184.2.163.

26. Zeppegno P, Airoldi P, Manzetti E, Panella M, Renna M, Torre E. Involuntary psychiatric admissions: A retrospective study of 460 cases. Eur J Psychiat. 2005;19(3):133-143. doi:10.4321/ S0213-61632005000300001.

27. Schuepbach D, Novick D, Haro JM, et al. Determinants of voluntary vs. involuntary admission in bipolar disorder and the impact of adherence. Pharmacopsychiatry. 2008;41(1):29-36. doi:10.1055/s-2007-993213. 